\title{
Prevalence of Plasmodium Parasitaemia among Blood Donors in Port Harcourt, Nigeria
}

\author{
Kennedy T. Wariso*, Ibinabo L. Oboro \\ Department of Medical Microbiology and Parasitology, University of Port Harcourt Teaching Hospital, Port \\ Harcourt, Nigeria \\ Email: "Kennedy.wariso@yahoo.com
}

Received 7 April 2015; accepted 14 May 2015; published 18 May 2015

Copyright (C) 2015 by authors and Scientific Research Publishing Inc.

This work is licensed under the Creative Commons Attribution International License (CC BY). http://creativecommons.org/licenses/by/4.0/

(c) (1) Open Access

\begin{abstract}
Globally, efforts are being intensified to control and possibly eliminate malaria. Transfusion transmitted Malaria unfortunately still occurs commonly in malaria endemic countries such as Nigeria and may continue to hamper efforts at control of malaria because blood donors are not routinely screened for malaria before donation. This study was carried out to determine the prevalence of Plasmodium Parasitaemia among blood donors who presented in our institution between 2012 and 2014, using light microscopy. Among the 200 donors studied, 135 (67.5\%) were infected. Males $(\mathbf{9 7 . 5 \% )}$ were statistically more than females $(2.5 \%)$ but infection rate was higher among the female population ( $100 \%$ as against $66.7 \%$ in males), with this difference being statistically significant. All donors were infected with Plasmodium falciparum with the majority of the donors having mild to moderate degrees of Parasitaemia. Women (52.5\%) and children (17.5\%) formed the bulk of recipients for which blood was donated. The high prevalence of Plasmodium Parasitaemia among blood donors in Port Harcourt highlights the need for more efforts to be targeted at preventing transmission of malaria via blood transfusion as this will ultimately contribute to reduction in the incidence of malaria and indeed its control/elimination in Nigeria.
\end{abstract}

\section{Keywords}

Transfusion Malaria, Blood Donors, Plasmodium falciparum

\section{Introduction}

Malaria is a parasitic infection caused by species of the Plasmodium parasite which are transmitted by the bite of

"Corresponding author. 
an infected female Anopheles mosquitoe [1].

There are presently five species of the Plasmodium parasite that have been known to infect man. They are Plasmodium falciparum (P. falciparum) which is endemic in Nigeria and West Africa, Plasmodium ovale, Plasmodium vivax, Plasmodium malariae and Plasmodium knowlesi [2]. The species differ widely in morphology, geographical distribution, characteristics and clinical presentations [3].

It is endemic in Nigeria and sub-Saharan Africa due to all round presence of the parasite Plasmodium falciparum, and the efficient transmission by its mosquitoe vectors [4].

In Nigeria, it is a major public health problem where it accounts for more cases and deaths than in any other country in the world [5].

It has been stated that ninety-seven percent (97\%) of Nigeria's population is at risk of malaria whereas the remaining $3 \%$ of the population live in the malaria free highlands [5].

According to the world health organisation, during 2013, an estimated 128 million people were infected with P. falciparum in sub-Saharan Africa at any one time. In total, 18 countries accounted for $90 \%$ of infections in sub-Saharan Africa; 37 million infections (29\%) arose in Nigeria and 14 million (11\%) in the Democratic Republic of the Congo, the two countries with the highest numbers of infections. These figures only included patent infections (i.e. those detectable using routine microscopy or rapid diagnostic tests). The numbers of lowdensity sub patent infections across Africa are believed to be considerably higher [6].

The contribution of malaria to morbidity and mortality rates in Nigeria, especially among pregnant women and children cannot be over-emphasized. It contributes an estimated $11 \%$ of maternal mortality, accounts for $60 \%$ of outpatient visits and for $30 \%$ of hospitalizations among children under five years of age in Nigeria. The greatest prevalence (about 50\%) occurs in children aged 6 - 59 months in the South West, North Central, and North West regions and the least prevalence of $27.6 \%$ was found in children aged six to fifty-nine (6 to 59) months in the South East region of the country [5].

It is the second leading cause of death from infectious diseases in Africa, after HIV/AIDS and almost one out of five deaths of children less than five years in Africa are due to malaria [5].

Worldwide, malaria affects 3.3 billion people or half of the world's population, in 106 countries and territories and is the third $\left(3^{\text {rd }}\right)$ leading cause of death for children under five years, after pneumonia and diarrheal disease [5] [6].

According to the World Health Organization, in 2012, an estimated 207 million malaria cases (80\% in the African region) and 627,000 global malaria deaths occurred worldwide (90\% in the African Region) while in 2013, an estimated 198 million cases and 584,000 deaths from malaria occurred (mostly among African children) indicating some achievement in the efforts towards control of malaria, however, in 2014, 97 countries still had ongoing malaria transmission [6] [7].

Other than the parasites being transmitted following the bite of an infected female Anopheles mosquitoe, Plasmodium parasites can be transmitted through other means. Well documented modes of transmission are from person to person via blood transfusion and organ transplantation, via needle stick injury and from mother to child [8].

Malaria can be transmitted by transfusion of blood from infected donors. First reported in 1911, transfusion malaria is one of the most common transfusion-transmissible infections [9] [10].

Erhabor and co-researchers recorded a 10.2\% prevalence of Plasmodium parasitemia among blood donors in the Niger delta region of Nigeria [11].

The parasite can survive for 3 weeks or more in refrigerated blood. The risk of transmission is even higher in cases of transfusion of fresh whole blood, particularly when the blood has been stored for less than 5 days with the risk being reduced considerably after 2 weeks [12] as well as in situations where transfusion of plasma, plasma components, or derivatives devoid of intact red cells is practiced [13] [14].

Most donors implicated in transfusion-transmitted malaria are predominantly semi-immune with very low parasite loads and the infectious dose is estimated to be 1 to 10 parasites in a unit of blood. Asexual forms are directly inoculated into the blood and pre-erythrocytic development of the parasite in the liver does not occur. Therefore, this has a shorter incubation period and can progress rapidly into fatal illness. Relapses due to persisting exo-erythrocytic forms do not occur.

Malaria also causes anemia which may require blood transfusions, a procedure that further increases the risk for malaria and for Human Immunodeficiency Virus (HIV) infection especially in settings where universal blood screening is yet to be achieved. People living with HIV/AIDS (PLWHA) are also at an increased risk of clinical malaria, severe illness, hospitalization, and death from malaria. It is known to contribute to a temporary 
increase in viral load among HIV-infected people which may worsen their clinical disease, increase mother-to child transmission of HIV, and augment transmission among adults [5].

In Nigeria, blood transfusion is a very common practice. About one million units of blood are collected annually nationwide and this is just about half the estimated amount of blood required for transfusion [15].

Blood donors are not routinely screened for malaria parasites in the University of Port Harcourt Teaching Hospital (UPTH) prior to donation, therefore the risk of transmission of malaria parasites to blood recipients and the likelihood of their development of clinical disease remains high.

There is also no documented policy on the use of prophylactic anti-malarials in transfused patients and there is a paucity of knowledge about the prevalence and epidemiology of Plasmodium parasitaemia among blood donors in Port Harcourt.

This study was carried out to determine the prevalence of Plasmodium parasitaemia among blood donors in the University of Port Harcourt Teaching Hospital (UPTH), Port Harcourt, Rivers State, Nigeria.

\section{Methods}

This cross-sectional study was carried out in the University of Port Harcourt Teaching Hospital located in Port Harcourt, at the heart of the oil-rich Niger delta region of Nigeria. The UPTH is one of the only two tertiary health institutions in Rivers state and is highly patronized by a large proportion of people living in the southsouth and south-east geo-political zone of Nigeria.

Ethical approval was obtained from the ethical committee of the hospital before commencement. Consenting blood donors were recruited until the sample size of two hundred was achieved.

$2 \mathrm{ml}$ of venous blood was collected from each study participant using an Ethylene Diamine Tetra-acetic Acidcontaining vacutainer tube and needle. Thick and thin blood smears were made from these, allowed to air-dry and the thin films were fixed in methanol. All smears were then stained with $3 \%$ Giemsa solution for 30 minutes, thereafter washed with clean water and then left on staining racks to air-dry. Each was viewed under the light microscope at $100 \times$ magnification under oil immersion. Asexual stages of Plasmodium parasites were identified where present and quantified.

Data obtained from this study was analyzed using the statistical package Epi-info version 7.02. Chi-Square $\left(\chi^{2}\right)$ test was employed with the level of significance set at $p<0.05$.

\section{Results}

The sex and age distribution of the donors screened in this study as well as their infection rates according to sex and age groups are shown in Table 1. The mean donor age was $32.13 \pm 6.25$ (mean \pm SD) with a range of twenty-one (21) to forty-five (45) years.

The majority of donors accounting for $97.5 \%$ (195) were male while females accounted for just $2.5 \%$ (5) of all donors screened with the difference being significant statistically ( $\chi^{2}=361.00, p$-value $=0.001$ ). All five female donors were infected while only $66.7 \%$ of males were infected. This difference in infection rates between the sexes was statistically significantly $(p=0.001)$.

The largest proportion of donors (55\%) belonged to the age group twenty-six to thirty-five years, followed by the thirty-six to forty-five year age group $(25 \%)$ while those $\leq 25$ years were least $(20 \%)$. On the other hand, the highest infection rate occurred among donors who were $\leq 25$ years. This difference in infection percentage between the various age groups was statistically significant $\chi^{2}=64.50, p=0.001$ ).

The Prevalence rate of Plasmodium parasitaemia among blood donors in this study was $67.5 \%$ (Table 2).

Table 3 shows the degree of parasitaemia among the donors who were infected, most (47.5\%) of who had only a mild degree of parasitaemia.

All positive donors in this study were infected with the specie Plasmodium falciparum.

Figure 1 shows the age and sex distribution of recipients; Children (age $\leq 17$ years) made up 17.5\% of recipients while adults ( $\geq 18$ years) made up $82.5 \%$ of recipients. Females recipients (57.5\%) exceeded males (42.5\%) with adult females accounting for $52.5 \%$ of all recipients.

The recipients were between 9 days to 69 years of age, with a mean of $34.10 \pm 17.67$ (mean \pm SD) years.

\section{Discussion}

Transfusion malaria in Nigeria has unfortunately remained a very common complication of blood transfusion. 
Table 1. Age and sex distribution of donors and the prevalence of malaria parasites according to sex and age.

\begin{tabular}{|c|c|c|c|}
\hline Characteristics & Frequency (\%) & Chi-square $\left(\chi^{2}\right)$ & p-value \\
\hline \multicolumn{4}{|c|}{ a) Sex Distribution of Donors } \\
\hline Male & $195(97.5)$ & 131.64 & $0.001^{*}$ \\
\hline Female & $5(2.5)$ & & \\
\hline Total & $200(100.0)$ & & \\
\hline \multicolumn{4}{|c|}{ b) Prevalence of Malaria Parasites in Donors According to Sex } \\
\hline Male & $130(96.30)$ & 83.25 & $0.001^{*}$ \\
\hline Female & $5(3.70)$ & & \\
\hline Total & $135(100.0)$ & & \\
\hline \multicolumn{4}{|c|}{ c) Age Distribution of Donors } \\
\hline$\leq 25$ & $40(20.0)$ & 64.50 & $0.001^{*}$ \\
\hline $26-35$ & $110(55.0)$ & & \\
\hline $36-45$ & $50(25.0)$ & & \\
\hline Total & $200(100.0)$ & & \\
\hline \multicolumn{4}{|c|}{ d) Prevalence of Malaria Parasites in Donors by Age Groups } \\
\hline$\leq 25$ & $30(22.2)$ & 45.00 & $0.001^{*}$ \\
\hline $26-35$ & $75(55.6)$ & & \\
\hline $36-45$ & $30(22.2)$ & & \\
\hline Total & $135(100.0)$ & & \\
\hline
\end{tabular}

${ }^{*}$ Significant if $p$-value $<0.005$.

Table 2. Prevalence of Plasmodium Parasitaemia among blood donors using giemsa-stained blood films.

\begin{tabular}{ccc}
\hline Plasmodium Parasites in Blood & Frequency & Percentage \\
\hline Positive & 135 & $67.50 \%$ \\
Negative & 65 & $32.50 \%$ \\
Total & 200 & $100.00 \%$ \\
\hline
\end{tabular}

$\chi^{2}=15.86, p$-value $=0.001$.

Table 3. Parasite density among donors with positive Parasitaemia.

\begin{tabular}{ccc}
\hline Degree of Parasitaemia & Frequency & Percentage \\
\hline Mild (+) & 95 & $47.50 \%$ \\
Moderate (2+) & 40 & $20.00 \%$ \\
Total & 135 & $67.50 \%$ \\
$\chi^{2}=14.40$-value $=0.001$ & & \\
\hline
\end{tabular}

$+=1$ - 10 parasites/100 high power fields. $2+=>10$ parasites/100 high power fields.

The prevalence rate of $67.5 \%$ recorded in this study shows that it is still a major health challenge in Nigeria. This rate though higher than that observed by Erhabor and colleagues in the Niger Delta region of Nigeria as well as by other researchers in Ghana, [11] [16] is quite similar to that observed in other parts of Nigeria with rates ranging from $51.5 \%$ to $77.4 \%$ prevalence of plasmodium parasitaemia among blood donors [17]-[20]. 


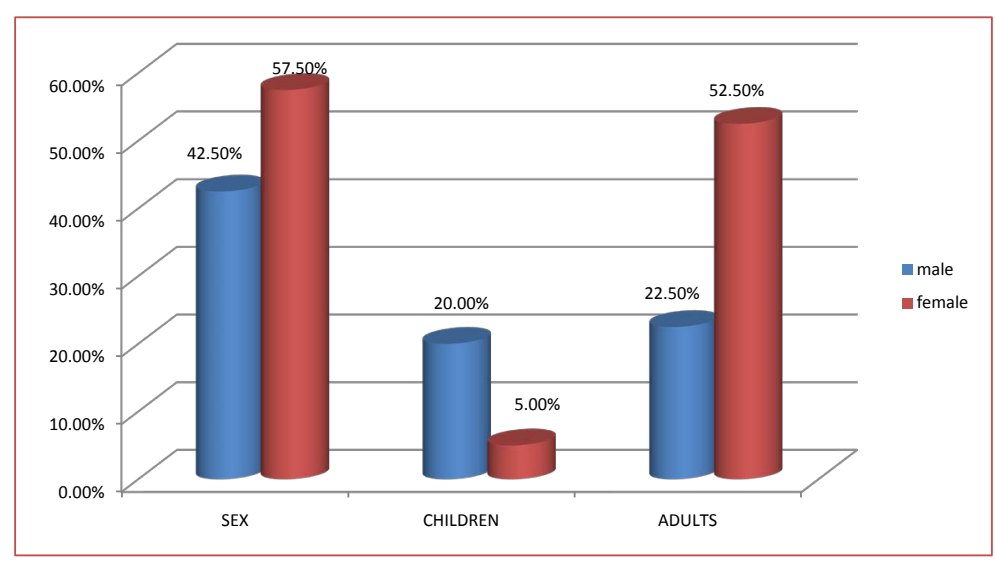

Figure 1. Age and sex distribution of recipients.

The high prevalence rate is probably due to the fact that malaria being endemic in Nigeria, has a stable and intense transmission in the country; therefore due to a high degree of acquired resistance to the plasmodium parasites, individuals resident $\mathrm{n}$ this geographical area may harbour parasites without obvious clinical manifestations. Such infected but asymptomatic donors thus pose a threat to the recipients of their blood who could come down with transfusion malaria.

In addition, commercial blood donation which is still a common practice in our country has been associated with a higher rate of transfusion malaria so may have contributed to the high rate observed [21].

This is further supported by our findings that all infected donors had mild to moderate degrees of parasitaemia; ninety-five (47.5\%) had mild while forty (20\%) had moderate degrees of parasitaemia. None had heavy parasitaemia. This low level of parasitaemia in an endemic area may not result in clinical manifestations among the donors who may then transmit the infection to the unsuspecting recipients of their blood.

The higher infection rate among women is similar to the findings of Otajevwo and of Vlassoff and Bonilla [22] [23] but differs from the finding by Muntaka and Opoku-Okrah in Ghana as well as Mbanugo in Owerri, Nigeria, where males had a higher plasmodium parasite infection rate than females [16] [20] and that by Badger-Emeka and co-researchers [19] who found no significant difference in infection rates among the sexes.

The highest infection rate occurred among younger donors ( $\leq 25$ years). It is similar to that observed by Muntaka and co-researchers and might be a reflection of the risk taking behaviour of adolescents and young adults who are also less likely to pay much attention to malaria control practices such as sleeping under insecticide treated bed nets, wearing of protective sleep wear and use of insecticides/environmental modification.

It is also important to note that recipients of blood who may be in poor state of health/immunocompromised are more likely to develop severe clinical manifestations of malaria if infected. This gives us great concern as the age groups most susceptible to the devastating effects of malaria especially that of severe malaria caused by $P$. falciparum made up a significant proportion of recipients for which blood was donated in this study: women accounted for $52.5 \%$ and children $17.5 \%$ [6].

All positive donors in this study were infected with the specie Plasmodium falciparum which is neither surprising nor a solitary finding; P. falciparum is the specie most endemic in sub-Saharan Africa, is associated with severe malaria and responsible for most deaths from malaria [4] [16].

With regards to the economy, the age range between 21 and 45 years (which is within the recommended age limits for blood donors in Nigeria) to which the donors in this study belonged forms the bulk of our workforce and therefore clinical disease in this group of individuals could lead to loss of manpower and thus have a negative economic impact on the country besides the adverse health effects.

The significantly higher number of male donors than females is neither unexpected nor different from findings in various other parts of the country and might be due to the fact women are generally discouraged from donating blood owing to the belief that women have less blood because of blood lost during their monthly menstruation and childbirth [24].

\section{Conclusions/Recommendations}

The high prevalence of Plasmodium Parasitaemia among blood donors in Port Harcourt highlights the need for 
more efforts to be targeted at controlling malaria among this group of individuals as this will ultimately lead to a reduction in the incidence of malaria in Nigeria.

It is recommended that intending donors be screened and treated for malaria where positive prior to donation of blood.

Routine/regular blood donations should be encouraged so as to prevent blood donations from being made under emergency situations because in such cases the likelihood of transfusing infected blood will be higher.

Blood bank policies should be improved to encourage freewill donations by individuals to help increase the stock of malaria-free blood for transfusion.

Regular and impactful awareness campaigns on the benefits of regular free blood donations by well meaning citizens will also help reduce the need for emergency donations and their negative consequences.

\section{References}

[1] Malaria. http://www.who.int/topics/malaria/en/

[2] Cook, G.C. and Zumla, A. (2009) Malaria. Manson’s Text Book of Tropical Diseases. 22nd Edition, Saunders Press, London, 1201.

[3] Wariso, K.T. (2007) Comparison between Malaria Parasite Positivity by Light Microscopy and Rapid Antigen Test among Suspected Malaria Patients in University of Port Harcourt Teaching Hospital. TNHJ, 7, 491-494.

[4] Federal Ministry of Health, Nigeria. (2005) National Malaria and Vector Control Division. Report on Malaria Control Strategies in Nigeria.

[5] Nigeria Malaria Fact Sheet. United States Embassy in Nigeria. http://nigeria.usembassy.gov

[6] World Health Organization (2014) World Malaria Report. http://www.who.int/malaria/publications/world_malaria_report_2014/report/en/

[7] World Health Organisation (2014) Malaria Fact Sheet No. 94. http://www.who.int/mediacentre/factsheets/fs094/en/

[8] A.D.A.M. Medical Encyclopedia. Malaria. Quartan Malaria; Falciparum Malaria; Biduoterian Fever; Blackwater Fever; Tertian Malaria; Plasmodium. http://www.ncbi.nlm.nih.gov/pubmedhealth/PMH0001646/

[9] Chauhan, V., Negi, R.C., Verma, B. and Thakur, S. (2009) Transfusion Transmitted Malaria in a Non-Endemic Area. JAPI, 57, 653-654. http://www.japi.org/september_2009/article_09.pdf

[10] Slinger, R., Giulivi, A., Bodie-Collins, M., Hindieh, F., St. John, R., Sher, G., Goldman, M., Ricketts, M. and Kain, K.C. (2001) Transfusion-Transmitted Malaria in Canada. CMAJ, 164, 377-379. http://www.cmaj.ca/cgi/reprint/164/3/377.pdf

[11] Erhabor, O., Ok, O., Awah, I., Uko, K.E. and Charles, A.T. (2007) The Prevalence of Plasmodia parasitaemia among Donors in the Niger Delta of Nigeria. Tropical Doctor, 37, 32-34. http://dx.doi.org/10.1258/004947507779951998

[12] Editorial: Transfusion Malaria in Developing Countries. British Medical Journal, 1, 542. http://www.ncbi.nlm.nih.gov/pmc/articles/PMC1639338/pdf/brmedj00506-0010a.pdf http://dx.doi.org/10.1136/bmj.1.6009.542

[13] Johnson, B., Brown, J.H., Yoedino, R., et al. (1983) Transfusion Malaria: Serologic Identification of Infected Donors-Pennsylvania, Georgia. MMWR Weekly, 32, 222-224, 229. http://www.cdc.gov/mmwr/preview/mmwrhtml/00000073.htm

[14] American Association of Blood Banks (2011) Standards for Blood Banks and Transfusion Services. 27th Edition, Bethesda, MD.

[15] Ejele, O.A. (2012) Blood Sacrifice-How Saving? Inaugural Lecture Series No 85. 10th May, 2012. University of Port Harcourt Press, University of Port Harcourt, Port Harcourt. http://www.uniport.edu.ng/files/Inaugural Lectures/85 ${ }^{\text {th }}$ Inaugural Lecture-2012 by Prof O_A_Ejele.pdf

[16] Muntaka, S. and Opoku-Okrah, C. (2013) The Prevalence of Malaria Parasitaemia and Predisposition of ABO Blood Groups to Plasmodium falciparum Malaria among Blood Donors at a Ghanaian Hospital. AU Journal of Technology, 16, 255-260.

[17] Epidi, T.T., Nwani, C.D. and Ugorji, N.P. (2008) Prevalence of Malaria in Blood Donors in Abakaliki Metropolis, Nigeria. Scientific Research and Assay, 3, 162-164.

[18] Ekwunife, C.A., Ozumba, N.A., Eneanya, C.I. and Nwaorgu, O.C. (2011) Malaria Infection among Blood Donors in Onitsha Urban, Southeast Nigeria. Sierra Leone Journal of Biomedical Research, 3, 21-26. http://dx.doi.org/10.4314/sljbr.v3i1.66647

[19] Badger-Emeka, L., Emeka, P. and Egbu, V. (2013) Prevalence of Malaria Plasmodium Parasite among Blood Donors at Nsukka Area, Southeast Nigeria. BEST: International Journal of Humanities, Arts, Medicine and Sciences, 1, 45-50. 
[20] Mbanugo, J.I. and Emenalo, S. (2004) Prevalence of Malaria Parasitaemia among Blood Donors in Owerri, Imo State, Nigeria. Nigerian Journal of Parasitology, 25, 75-80.

[21] Enosolease, M.E., Imarengiaye, C.O. and Awodu, O.A. (2004) Donor Blood Procurement and Utilisation at the University of Benin Teaching Hospital, Benin City. African Journal of Reproductive Health, 8, 59-63. http://dx.doi.org/10.2307/3583178

[22] Otajevwo, F.D. (2013) Prevalence of Malaria Parasitaemia and Its Association with ABO Blood Grouping among Students of Igbinedion University Okada, Nigeria. British Journal of Medicine and Medical Research, 3, 1164-1177 http://dx.doi.org/10.9734/BJMMR/2013/1745

[23] Vlassoff, C. and Bonilla, E. (1994) Gender-Related Differences in the Impact of Tropical Diseases on Women: What Do We Know? Journal of Biosocial Science, 26, 37-53. http://dx.doi.org/10.1017/S0021932000021040

[24] Olaiya, M.A., Alakija, W., Ajala, A. and Olatunji, R.O. (2004) Knowledge, Attitudes, Beliefs and Motivations towards Blood Donations among Blood Donors in Lagos, Nigeria. Transfusion Medicine, 14, 13-17. http://dx.doi.org/10.1111/j.0958-7578.2004.00474.x 